\title{
Rabaska
}

Revue d'ethnologie de l'Amérique française

CLÉMENT, DANIEL. La Terre qui pousse. L'ethnobotanique innue d'Ekuanitshit. Québec, Presses de l'Université Laval, « Mondes autochtones », 2014, 247 p. ISBN 978-2-7637-2298-6

\section{Marcel Bénéteau}

Volume 14, 2016

URI : https://id.erudit.org/iderudit/1037470ar

DOI : https://doi.org/10.7202/1037470ar

Aller au sommaire du numéro

Éditeur(s)

Société québécoise d'ethnologie

ISSN

1703-7433 (imprimé)

1916-7350 (numérique)

Découvrir la revue

Citer ce compte rendu

Bénéteau, M. (2016). Compte rendu de [ClÉMENT, DANIEL. La Terre qui pousse. L'ethnobotanique innue d'Ekuanitshit. Québec, Presses de l'Université Laval, « Mondes autochtones », 2014, 247 p. ISBN 978-2-7637-2298-6]. Rabaska, 14,

236-239. https://doi.org/10.7202/1037470ar d'utilisation que vous pouvez consulter en ligne. 
Clément, Daniel. La Terre qui pousse. L'ethnobotanique innue d'Ekuanitshit. Québec, Presses de 1'Université Laval, « Mondes autochtones », 2014, 247 p. ISBN 978-2-7637-2298-6.

Ce livre de Daniel Clément arrive bien à point, au moment où les gens s'intéressent de plus en plus aux pratiques médicinales traditionnelles, voire naturelles, et se questionnent davantage sur les grandes questions environnementales : quelle est la place de l'être humain dans le monde naturel? quels sont les liens entre la culture et l'environnement? Une culture est-elle un produit naturel de son environnement, ou est-elle, par sa définition même, forcément en position antagoniste au monde naturel ? L'opinion courante concernant la culture occidentale contemporaine tend certainement vers cette deuxième interprétation ; l'analyse ethnologique de la culture traditionnelle innue, par contre, suggère un autre point de vue.

La Terre qui pousse est une réédition de L'Ethnobotanique montagnaise de Mingan ; publié en 1990, ce dernier ouvrage repose sur des enquêtes de terrain menées en 1980, 1981 et 1983 en préparation d'un mémoire de maîtrise en anthropologie. La nouvelle édition met à jour la terminologie «par respect pour les autochtones [...] qui préfèrent, de loin, utiliser leur propre vocabulaire pour s'identifier », mais aussi développe davantage les rapports entre les Innus et leur environnement. Les enquêtes originales se déroulèrent sur trois plans. D'abord, botanique, par le prélèvement et l'identification de spécimens de deux cents espèces de plantes. En deuxième lieu, une approche ethnobotanique consistant à recueillir des données - passées et présentes - sur les connaissances des végétaux. Enfin, une démarche plutôt anthropologique cherchant à saisir théoriquement le rapport homme-nature par une analyse détaillée de la communauté.

Le lecteur cherchant un simple guide pratique à la flore de la forêt boréale et à son utilisation restera sur sa faim; mais la lecture de cette étude ouvre plusieurs autres voies de réflexion sur le rôle de la langue et de la culture dans la façon dont une population perçoit le monde qu'elle habite et la place qu'elle occupe dans cet environnement. Le livre se veut avant tout un examen des bases sur lesquelles les Innus s'appuient pour structurer leurs connaissances ethnobotaniques : comment classifient-ils les plantes dans leur environnement (non seulement par rapport aux autres plantes, mais aussi par rapport aux autres êtres animés et non animés de leur univers) ainsi que les principes de nomenclature qui soutient le lexique botanique?

Pas étonnant, alors, que le premier chapitre du livre présente un survol des théories et concepts concernant la langue et la culture, commençant avec les études classiques de Sapir et Whorf et les débats concernant le rôle de la langue soit en reflétant ou en créant la réalité. Clément poursuit les courants 
linguistiques qui ont guidé le développement de l'ethnobotanique comme science. L'auteur rejette les théories des ethnoscientifiques étatsuniens des années 1960 et 1970 (Brown, Garner, Berlin) qui tentent d'expliquer toutes les relations par le bilan linguistique en faveur d'un retour aux théories intermédiaires des années 1950 (Brown et Harris) qui tiennent compte de facteurs métalinguistiques dans l'organisation du système de nomenclature et de formation de la culture. Pour Clément, il importe que les « principes taxinomiques soient replacés dans le contexte du savoir vernaculaire et, de ce fait, traités comme une manifestation d'une structure de relations qui comprendrait également d'autres manifestations telles l'utilisation du milieu, la place attribuée à l'être humain dans l'univers ou encore la façon vernaculaire de nommer les éléments de l'environnement. » Il conclut de façon qui nous semble tout à fait raisonnable que « l'appréhension de la réalité relève d'une complexité d'éléments, la catégorisation linguistique n'étant qu'un seul de ces éléments. »

Le deuxième chapitre décrit en détail le terrain, la population étudiée et la méthodologie employée. L'étude cible la communauté d'Ekuanitshit sur la côte nord du Saint-Laurent, à $160 \mathrm{~km}$ à l'est de Sept-Îles. À l'époque de l'enquête, la population en question abandonne de plus en plus ses activités de pêche, trappe et chasse et, donc, motive la cueillette rapide du savoir botanique « en train de se transformer profondément, sinon de se perdre. » Les données ont donc été recueillies principalement auprès des personnes les plus âgées : « celles qui, par leurs fréquents voyages à l'intérieur des terres, ont plus "connu" la végétation »; c'est aussi, peut-on supposer, le segment de la population qui maîtrise le mieux la langue innue. Selon l'auteur, le terrain de la forêt boréale s'avère idéal pour ce genre d'étude car : « le nombre relativement peu élevé d'espèces végétales permettait alors de délimiter un sujet d'étude assez restreint pour examiner en détail la totalité des interactions. »

Le chapitre suivant présente une analyse des concepts innus relatifs à la vie des plantes. Dans le monde créé par Carcajou, on reconnaît trois grands domaines : la terre, les animaux, les humains. Il n'y a aucun domaine comme tel qui correspond aux éléments botaniques ; l'auteur indique qu'on peut toutefois généraliser le concept de plantes comme « ce qui pousse dans la terre », bien que celles-ci partagent aussi des éléments avec les animaux et même les humains. Les lichens, mousses et les sphaignes, sans racines, sont littéralement « la terre qui pousse » (tout comme la vase, le tapis végétal et le bois en décomposition). Les plantes herbacées, les fleurs, les arbustes et les arbres, ayant tous des racines, se retrouvent à un niveau plus élevé. Les arbres (mishtukuat) sont considérés les plus importants dans cette hiérarchie, 
d'abord sur le plan identitaire : les Innus voient une étroite relation entre les parties de l'arbre et les parties du corps humain. Tous les deux sont soutenus par la terre (la racine/les jambes), se soutiennent grâce à leur colonne vertébrale (le tronc), possèdent des membres (branches/bras et mains); on va jusqu'à trouver une équivalence entre la gomme d'épinette et la morve et le sperme qui sortent des orifices humaines. On attribue même la parole au mélèze (uâtshinâkan), à l'épinette blanche (minaik) et à l'épinette noire (ushkâtuk) puisqu'ils servent à la fabrication de piquets pour la tente tremblante. Les arbres se situent également en haut de la hiérarchie en raison de leur fréquence d'utilisation par les Innus, que ce soit sur le plan médicinal, technique ou alimentaire. On apprend aussi que la dénomination des plantes et de leurs parties peut varier selon qu'elles soient utilisées par des hommes ou des femmes, ces dernières prédominant dans l'emploi médicinal tandis que les hommes sont surtout responsables pour les utilisations techniques.

La question de nomenclature et d'identification est abordée plus formellement dans les quatrième et cinquième chapitres, dans lesquels les lexèmes et morphèmes sont fortement reliés aux principes taxinomiques et morphologiques. Par exemple, vingt-trois lexèmes contiennent le suffixe-akashi, c'est-à-dire " plante à fruits » (par exemple, nishtshiminâkashî, « airelle des marais »). D'autres sont nommés d'après les fonctions de la plante en question; par exemple, le lexème tshishiteu-nîpîsha «les feuilles qui réchauffent » (c'est-à-dire employées pour traiter la fièvre) figure dans des termes utilisés par les femmes : kâuîpapinamâpukâshtiti nîpîsha "baume » et kâuâpishtukuâniâshtiti tshishiteu-nîpîsha " herbe à dinde ». L'analyse linguistique développée au cours de ces deux chapitres conclut effectivement que «l'utilisation des végétaux par une communauté peut avoir des répercussions sur le développement lexémique contingent $»$.

Les chapitres six et sept vont au-delà de l'analyse linguistique pour miser plus spécifiquement sur l'utilisation des plantes. Ce sont aussi ces deux chapitres qui nous instruisent le plus sur les applications pratiques des plantes. Ces utilisations sont réparties sur trois plans : technique, médicinal et alimentaire. Sur le plan technique, ce sont les arbres qui prédominent; une liste partielle des emplois du bois nous donne une idée des connaissances dans ce domaine ; par exemple, pour fabriquer le toboggan : patins en mélèze ou en épinette blanche et plancher en épinette noire ; pour le fût des raquettes : le bouleau blanc ou le mélèze, les barres transversales en épinette noire; pour des manches de hache, le cormier; branches de sapin ou d'épinette pour les planchers.

La critique de l'ethnobotanique, qui, selon l'auteur, a trop longtemps chercher à imposer des critères scientifiques de l'extérieur pour expliquer la 
taxinomie et la nomenclature d'un peuple, est implicite dans ces chapitres. Clément propose ici une approche plutôt de l'intérieur, basée sur la vision du monde de la communauté et sur l'utilisation concrète des végétaux. Ou pour citer le bilan de cette étude que l'auteur affirme dans sa conclusion : " Si on accepte que la taxinomie n'est qu'une manifestation langagière d'un système plus profond qui unit des êtres humains à une composante de leur milieu, et qui est basée sur un système partonomique et utilitaire, il se pourrait bien que ce soit plutôt d'autres facteurs tels l'utilité des espèces qui dictent en quelque sorte l'apparition des termes. »

Cette étude touche à l'ethnologie, certes, mais aussi à l'ethnoscience, à la sémantique et à la métalinguistique. Il s'agit d'un ouvrage scientifique qui s'avère difficile pour le non-expert dans ces domaines. De loin l'élément le plus utile et le plus abordable pour le lecteur profane réside dans le « Lexique botanique innu » qui paraît en annexe à la fin du livre (p. 224-247). Ce résumé brillant donne, sous forme de tableau, les lexèmes montagnais, français et latin pour chacune des 200 espèces relevées. Il indique ensuite ses emplois techniques, médicaux ou alimentaires par les hommes et les femmes ainsi que son étymologie de façon à bien illustrer les principes de nomenclature en jeu et leur lien avec la vision du monde innue. Il aurait été à souhaiter que l'auteur intègre ces illustrations succinctes davantage à son texte, ou du moins qu'il y renvoie le lecteur plus souvent dans le développement des arguments théoriques. Il reste que ce livre est une œuvre de profonde érudition, basée sur des enquêtes exemplaires et qui fait ressortir les liens entre langue, culture et territoire.

Marcel Bénéteau Université de Sudbury

Corriveau, Claude. Saint-Jean-Baptiste. Guide d'autovisite. Quatre circuits. Québec, Comité du patrimoine de Saint-Jean-Baptiste, 2015, 63 p. ISBN 9782981227829.

Dans la majestueuse nef de l'église Saint-Jean-Baptiste de Québec avait lieu, le $1^{\text {er }}$ mai 2015 , le lancement d'un guide d'autovisite du patrimoine religieux du quartier du même nom ; brochure de 63 pages couleur publiée par le Comité du patrimoine de Saint-Jean-Baptiste avec l'appui financier de l'arrondissement de la Cité-Limoilou et du Secrétariat de la Capitale-Nationale. Le Guide propose quatre circuits de visites à pied : le premier invite à découvrir onze lieux patrimoniaux en une heure et demie ; le deuxième, cinq en trente minutes; le troisième, vingt en deux heures ; le quatrième enfin, cinq en une heure. À ces quatre circuits de visites à pied, s'ajoute le cimetière Notre-Dame-de-Belmont, situé « à quelques minutes en 